\title{
Modelos mentales de estudiantes de educación secundaria sobre la transformación de la leche en yogur
}

\author{
Verónica Muñoz-Campos ${ }^{1, a}$, Antonio Joaquín Franco-Mariscal ${ }^{1, \mathrm{~b}}$, Ángel Blanco-López ${ }^{1, \mathrm{c}}$ \\ ${ }^{1}$ Departamento de Didáctica de las Ciencias Experimentales. Universidad de Málaga. Málaga. España \\ avmunoz@uma.es, bantoniojoaquin.franco@uma.es,_ablancol@uma.es
}

[Recibido: 7 agosto 2017. Revisado: 19 noviembre 2017. Aceptado: 25 enero 2018]

\begin{abstract}
Resumen: Los modelos mentales de los estudiantes proporcionan información valiosa sobre sus marcos conceptuales, es decir, sus estructuras de conocimiento subyacentes que pueden ayudar a mejorar el diseño de actividades de aprendizaje en el aula. Este trabajo investiga los modelos mentales de 153 estudiantes de secundaria obligatoria de entre 13 y 15 años sobre la transformación de la leche en yogur y propone un modelo escolar. Los datos se recogieron con dos tareas que demandaban explicar esta transformación a través de respuestas verbales y dibujos. A partir de las respuestas de los alumnos se identificaron siete modelos mentales, de los cuales cuatro (la fermentación es un proceso mecánico, implica un aumento en el número de bacterias, consiste en una mezcla macroscópica, y las bacterias como aglutinante de moléculas) deben considerarse como una aportación de este trabajo, al no haber sido identificados en estudios previos en esta etapa educativa. No obstante, los modelos están aún muy alejados del modelo escolar de fermentación láctica, por lo que se plantea la necesidad de recurrir a nuevas estrategias didácticas para avanzar en su progresión.
\end{abstract}

Palabras clave: modelos mentales; transformación de la leche en yogur; educación secundaria.

Secondary students' mental models about milk transformation into yogurt

Abstract: The students' mental models provide valuable information about their conceptual frameworks, that is, their underlying structures of knowledge that can help improve the design of the learning activities in class. This paper investigates the mental models of 153 secondary students aged 13 to 15, on the milk transformation into yogurt and a teaching model is proposed. The data were collected with two tasks that demanded to explain this transformation through verbal answers and drawings. Based on the students' responses, seven different mental models were identified, of which four (the fermentation is a mechanical process, implies an increase in the number of bacteria, it consists of a mixture, and the bacteria as a binder of molecules) must be regarded as a contribution of this work to not have been identified in previous studies in this educational stage. However, the models are still very far from the lactic fermentation school model, and new didactic strategies should be tried to move forward in their progression.

Keywords: mental models; milk transformation into yogurt; secondary education.

Para citar este artículo: Muñoz-Campos, V., Franco-Mariscal, A.J. y Blanco-Lopez, A. (2018) Modelos mentales de estudiantes de educación secundaria sobre la transformación de la leche en yogur. Revista Eureka sobre Enseñanza y Divulgación de las Ciencias 15 (2), 2106. doi: 10.25267/Rev_Eureka_ensen_divulg_cienc.2018.v15.i2.2106

\section{Introducción}

La química suele ser considerada por los estudiantes como una ciencia complicada debido, entre otros factores, a que su estudio se centra en entidades no visibles ni observables (Furió y Domínguez 2007), como, por ejemplo, cuando los fenómenos estudiados inciden en la relación entre biología y química. En este sentido, la utilización de modelos que permitan obtener una visión más simplificada de la estructura de la materia, podría contribuir a promover su aprendizaje. Diversos autores (Justi y Gilbert 2002; Oliva y Aragón 2009, entre otros) consideran que la enseñanza a través de modelos constituye una buena práctica para la adquisición de conocimientos científicos en educación secundaria.

El enfoque de modelización en didáctica de las ciencias consiste en abordar conceptos a través de representaciones simplificadas, que nos ayuden a construir y comprender el conocimiento y

\author{
Revista Eureka sobre Enseñanza y Divulgación de las Ciencias \\ Universidad de Cádi\%. APAC-Eureka. ISSN: 1697-011X \\ bttp:/ / dx.doi.org/10.25267/Rev_Eureka_ensen_divulg_cienc.2018.v15.i2.2106 \\ http:/ / reuredc.uca.es
}


el quehacer científico (Aragón 2012). Asimismo, los estudiantes aprenden los conocimientos científicos apoyándose en modelos que les resultan interesantes. Esto implica que no es suficiente la idea que los alumnos aprendan ciencias a través de modelos sino también deben ser capaces de elaborar estrategias, habilidades y actitudes necesarias para que puedan desarrollar modelos que les permitan entender algunos fenómenos.

Así, para que el enfoque de modelización ayude al alumnado a comprender mejor las ciencias, y a su vez una mejor comprensión de su entorno, el flujo de actividades de aprendizaje le debe resultar familiar y no muy complejo, ya que de este modo no se llegará a la monotonía y al aburrimiento. Según Prins (2010) el procedimiento para la modelización en el aula es de gran importancia en la enseñanza de las ciencias y debe estar ligado a las actividades propuestas. Desde nuestra perspectiva, no sólo se debe abordar la química desde una problemática real, sino que con el uso de modelos en el aula, el alumnado puede alcanzar a comprender esos problemas desde el punto de vista científico, que en un principio les podía resultar difícil de comprender y de asimilar (Prins et al. 2008).

Existen numerosas situaciones de la vida diaria que podrían ser el foco de interés para los estudiantes y que podrían aportar un aumento en su motivación, haciéndole ver la relación existente entre ciencia y vida diaria (Andrée 2005). El caso concreto que aquí nos ocupa utiliza el yogur como contexto de la vida cotidiana del alumno que puede resultar adecuado para la enseñanza y aprendizaje de un modelo de reacción química (Muñoz-Campos, Blanco-López y Franco-Mariscal 2015). El yogur se engloba dentro del grupo de alimentos fermentados, es decir, aquellos alimentos que han sido modificados por la actividad biológica de microorganismos. Dichos alimentos se pueden preparar a partir de materia cruda o tratada térmicamente, y es a través de una reacción química en la que intervienen microorganismos, generalmente bacterias, cuando se transforman y adquieren determinadas propiedades sensoriales y una mayor seguridad higiénica (Balaguer et al. 2006).

La fermentación es, por tanto, un proceso importante dentro del campo de la alimentación, ya sea de forma natural o industrial. Constituye un contenido del currículo escolar de ciencia de educación primaria (MEC 2014) y de Biología de $2^{\circ}$ de bachillerato (MEC 2015); si bien, no aparecen referencias a este término en los currículos de secundaria obligatoria. La fermentación también tiene interés en la investigación en enseñanza de las ciencias, ya que los estudiantes suelen mostrar modelos mentales alejados de los de la ciencia escolar (Sánchez 2005). Hay que tener presente, como indican Coll y Treagust (2003), que los modelos mentales de las personas son los instrumentos con los que se analizan las informaciones que les llegan y con los que se toman decisiones. Es por ello, que estudiar los modelos mentales iniciales de los estudiantes de secundaria sobre este tema puede ser útil al diseñar las actividades de aprendizaje.

Conocer en profundidad los procesos de transformación de leche en yogur, puede ayudar a los alumnos a analizar de una forma más rigurosa los mensajes que le llegan a través de los medios de comunicación; en particular, a través de la publicidad (Girón 2017), donde se incide en este tipo de productos destacando sus supuestos beneficios para la salud (Parra 2012). Sin embargo, a pesar de tratarse de un producto cotidiano muy consumido por los estudiantes, el proceso de la transformación de leche en yogur es un tema poco tratado en la educación secundaria, como marco para la comprensión de la reacciones bioquímicas (Jiménez-Liso, López-Gay y Márquez 2010).

Antes de diseñar una propuesta didáctica desde el enfoque de modelización, se deben conocer los modelos iniciales de los estudiantes (Clement 2000; Justi y Gilbert 2002). La transformación de leche en yogur es una parcela de investigación poco estudiada con este enfoque, ya que no se encuentran muchos trabajos que analicen los modelos que los 
estudiantes tienen sobre transformaciones químicas en las que intervienen seres vivos. Es por ello, que el presente trabajo se centre en la identificación de los modelos mentales de estudiantes de secundaria sobre la transformación de leche en yogur, y en la búsqueda de elementos que ayuden a encontrar líneas de progresión en los mismos. Esto supondrá el primer paso para el diseño de propuestas didácticas futuras, que ayuden a los estudiantes a avanzar en sus modelos.

\section{Fundamentación teórica}

Este apartado aborda en primer lugar algunas cuestiones sobre los modelos mentales y seguidamente se analizan los trabajos que han investigado las concepciones que tienen sobre la transformación de la leche en yogur.

\section{Modelos mentales de los estudiantes}

Un modelo consiste en una representación de un fenómeno que ayuda a explicar un concepto científico que entraña cierta dificultad (Caamaño 2011). La mayoría de los conceptos químicos han sido propuestos por científicos a través de modelos que les ayudan a entender su significado, por lo que los modelos se encuentran en una zona comprendida entre el fenómeno y la teoría (Gilbert, Boulter y Rutherford 1998). En términos generales, los modelos nos ayudan a comprender diversos fenómenos tanto científicos como no científicos y muchas veces el propio estudiante, sin ser consciente de ello, los aplica para explicar fenómenos de su vida diaria.

No se debe olvidar que los modelos representan una parte limitada de la realidad y deben entenderse como una simplificación de una realidad más compleja. Así pues, los diferentes modelos que se pueden generar durante la etapa escolar deben ser representaciones simples, que expliquen aspectos de la vida cotidiana de forma gradual (Acher 2014). En su elaboración se pueden utilizar diferentes recursos: dibujos, esquemas, maquetas, metáforas, analogías, simulaciones, etc. (Oliva y Aragón 2009).

Durante las tres últimas décadas la literatura sobre modelos mentales ha proliferado sustancialmente, existiendo una gran variedad de definiciones de este concepto. Sin embargo, todas ellas coinciden en que los modelos mentales son representaciones dinámicas y generativas que pueden manipularse mentalmente para proporcionar explicaciones causales de fenómenos físicos y hacer predicciones sobre su estado en el mundo físico (Vosniadou 1994). Son construidos por científicos y estudiantes para interpretar sus experiencias y para dar sentido al mundo físico y pueden servir a una serie de propósitos y funciones para proporcionar explicaciones y justificaciones (Coll y Treagust 2003). Por otra parte, diferentes autores (Norman 1983, Hafner y Stewart 1995) consideran que los modelos mentales son incompletos, no científicos y no tienen límites firmes. Sin embargo, Norman (1983) cree que los modelos se mantienen durante largos períodos de tiempo y son relativamente estables. Aunque los modelos mentales representan construcciones personales, existe el consenso de que están sujetos a influencia social (Coll y Treagust 2003).

Los modelos mentales son de interés por dos razones (Coll y Treagust 2003): por un lado, influyen en el funcionamiento cognitivo y, por otro, pueden proporcionar a investigadores y profesores de educación científica información valiosa sobre el marco conceptual de los alumnos, es decir, sus estructuras de conocimiento subyacentes (Vosniadou 1994), que pueden ayudar a mejorar el diseño de actividades en el aula. Por otra parte, diversos estudios (Ainsworth et al. 2011; Gómez y Gavidia 2015) demuestran la importancia de la utilización del dibujo en la enseñanza de las ciencias, indicando que aumenta la motivación en el aula, ayuda a 
la compresión de aspectos científicos y desarrolla estrategias de aprendizaje (Franco-Mariscal 2015).

\section{Modelo escolar sobre la fermentación láctica}

Identificar qué tipos de modelos tienen sentido y son productivos para los estudiantes en distintas etapas escolares es un punto crítico para implicarlos en la modelización (Acher 2014). Esto puede hacerse planteando un modelo escolar al que pretendemos que los estudiantes lleguen después del proceso de enseñanza-aprendizaje. Al elaborar un modelo escolar es necesario tener en cuenta, entre otros aspectos, la naturaleza del concepto que se desea analizar. De este modo, desde la perspectiva de Chi, Slotta y Leeuw (1994), la transformación de leche en yogur es un proceso, denominado fermentación láctica, que tiene lugar sólo en ciertas condiciones. Aunque en él puede intervenir un buen número de variables (Balaguer et al. 2006), desde una perspectiva escolar es aconsejable centrarse en sus componentes principales. Asimismo, hay que tener en cuenta que la finalidad del estudio es conocer los posibles modelos mentales de los alumnos sobre esta transformación como una reacción bioquímica. Así, el azúcar es el reactivo, el ácido láctico es el producto, y las bacterias (lactobacillus y streptococos) son los seres vivos que producen la transformación.

La formulación de un modelo muy simplificado del proceso de fermentación láctica podría hacerse de la siguiente forma: las bacterias utilizan el azúcar presente en la leche y lo transforman en ácido láctico, obteniendo así la energía necesaria para realizar sus funciones vitales. No obstante, este modelo, a pesar de su aparente sencillez, muestra una mayor complejidad que aquellos relativos a las transformaciones químicas de la materia inorgánica, ya que implica la integración de sistemas materiales en diversos niveles de organización molecular y organismos vivos. Hay que tener en cuenta que el modelo de ser vivo es complejo, no solo desde el punto de vista de su estructura (lo que permite relacionar cada uno de los órganos que lo componen con sus funciones), sino también desde las relaciones con el medio exterior. Gómez, Sanmartí y Pujol (2007) plantean un modelo de ser vivo como un sistema en el que interviene la nutrición (intercambio con el medio exterior energía y/o materia), la relación con su entorno, la reproducción (provienen de otros seres vivos) y, por último, que pueden estar constituidos por una o varias unidades estructurales llamadas células. En la propuesta que aquí se hace no se abordarán todos estos aspectos de las bacterias como seres vivos, centrándose exclusivamente en su papel en la reacción química de fermentación.

Para que el alumno alcance el modelo científico se debe partir del modelo escolar, que implica la articulación de una serie de factores y escalas de modelización. Se asume en el ámbito de la ciencia que para conseguir una adecuada compresión de los fenómenos químicos y biológicos, es necesario diferenciar los ámbitos macro, micro y submicroscópico en los que suceden (Oliva y Aragón 2009). Resulta, por tanto, importante conocer cómo se concibe el fenómeno en cada uno de estos niveles y cómo ayudar a que los estudiantes articulen las relaciones entre ellos.

Tomando en consideración estas ideas, para el caso concreto de la elaboración de yogur proponemos el modelo escolar mostrado en la tabla 1. 
Tabla 1. Modelo escolar para la transformación de la leche en yogur [elaboración propia]

\begin{tabular}{|c|c|c|c|c|}
\hline & Leche & Bacterias & Transformación & Yogur \\
\hline Macroscópico & $\begin{array}{l}\text { Se trata de un producto } \\
\text { natural en estado líquido } \\
\text { de color blanco y aspecto } \\
\text { homogéneo. La leche de } \\
\text { vaca es ligeramente ácida, } \\
\text { con un pH comprendido } \\
\text { entre } 6.5 \text { y } 6.8 . \\
\text { Aunque parezca } \\
\text { homogénea la leche tiene } \\
\text { numerosos componentes } \\
\text { (ver por ejemplo las } \\
\text { etiquetas). Entre ellos la } \\
\text { lactosa que también está } \\
\text { presente en otros muchos } \\
\text { productos. }\end{array}$ & & $\begin{array}{l}\text { Se produce un cambio de textura y } \\
\text { sabor y un descenso del } \mathrm{pH} \text {. }\end{array}$ & $\begin{array}{l}\text { Se trata de un } \\
\text { producto de color } \\
\text { blanco, de apariencia } \\
\text { homogénea y sabor } \\
\text { ácido (pH= 4-5), } \\
\text { producido por la } \\
\text { presencia de ácido } \\
\text { láctico. }\end{array}$ \\
\hline Microscópico & $\begin{array}{l}\text { Vista al microscopio, la } \\
\text { leche ya no aparece como } \\
\text { un producto homogéneo } \\
\text { y pueden verse distintos } \\
\text { componentes. Se trata de } \\
\text { un sistema material } \\
\text { denominado coloide. }\end{array}$ & $\begin{array}{l}\text { Las bacterias son seres } \\
\text { vivos microscópicos. En } \\
\text { la leche natural (no en las } \\
\text { pasteurizadas) están } \\
\text { presentes distintos tipos } \\
\text { de bacterias, entre las que } \\
\text { se encuentran las } \\
\text { denominadas } \\
\text { Lactobacillus. Vistas al } \\
\text { microscopio se puede ver } \\
\text { cómo se mueven y su } \\
\text { forma de bastones } \\
\text { alargados. }\end{array}$ & & $\begin{array}{l}\text { Visto al microscopio } \\
\text { el yogur no aparece } \\
\text { como un producto } \\
\text { homogéneo y pueden } \\
\text { verse distintos } \\
\text { componentes, entre } \\
\text { ellos las bacterias. }\end{array}$ \\
\hline $\begin{array}{l}\text { Submicroscó- } \\
\text { pico }\end{array}$ & $\begin{array}{l}\text { La fórmula de la molécula } \\
\text { de la lactosa es } \\
\mathrm{C}_{12} \mathrm{H}_{22} \mathrm{O}_{11}\end{array}$ & & $\begin{array}{l}\text { Las bacterias descomponen las } \\
\text { moléculas de lactosa en glucosa y } \\
\text { galactosa, que tienen la misma } \\
\text { fórmula molecular }\left(\mathrm{C}_{6} \mathrm{H}_{12} \mathrm{O}_{6}\right) \text {. Las } \\
\text { bacterias transforman las } \\
\text { moléculas de glucosa en ácido } \\
\text { láctico }\left(\mathrm{C}_{3} \mathrm{H}_{6} \mathrm{O}_{3}\right) \text { mediante la } \\
\text { siguiente reacción química: } \\
\qquad \text { Bacterias } \\
\mathrm{C}_{6} \mathrm{H}_{12} \mathrm{O}_{6} \rightarrow 2 \mathrm{C}_{3} \mathrm{H}_{6} \mathrm{O}_{3}+\text { Energía } \\
\mathrm{Glucosa}_{\text {Ácido láctico }} \\
\text { De esta forma las bacterias } \\
\text { obtienen la energía necesaria para } \\
\text { realizar sus funciones vitales } \\
(\text { respiración anaeróbica). } \\
\text { Este proceso se denomina } \\
\text { fermentación láctica y se produce } \\
\text { más rápidamente cuando la } \\
\text { temperatura está en torno a } 40 \text { - } \\
45^{\circ} \mathrm{C} \text {. }\end{array}$ & $\begin{array}{l}\text { La fórmula del ácido } \\
\text { láctico es } \mathrm{C}_{3} \mathrm{H}_{6} \mathrm{O}_{3}\end{array}$ \\
\hline
\end{tabular}


Para la compresión y la modelización de la transformación de la leche en yogur se han identificado como elementos clave: la leche y las bacterias (sistemas iniciales), la fermentación (el proceso) y el yogur (producto final) (tabla 1). Cada una de las celdas del modelo escolar muestra las ideas que se pretenden que los estudiantes alcancen en su aprendizaje.

Llegar a este modelo escolar supone un proceso gradual en el que los estudiantes deben ir modificando y ampliando sus modelos mentales iniciales. Por ello, es necesario conocer y contemplar los diversos modelos que los estudiantes pueden tener sobre la fermentación, hasta llegar al modelo escolar. Se trata de situar en un esquema de progreso las distintas formulaciones de los modelos que los alumnos tienen.

\section{Concepciones, ideas y/o modelos de los estudiantes sobre la transformación de leche en yogur}

Las investigaciones sobre modelos mentales de los estudiantes para relacionar conceptos que involucren la actividad biológica mediante reacciones químicas de microorganismos, y más específicamente de las bacterias en los procesos alimenticios, son muy escasas comparadas con las desarrolladas sobre otros fenómenos (Sánchez 2005). Cabe destacar la inclinación de los estudiantes por clasificar a las bacterias como agentes patógenos, desconociendo su actividad y aplicación en la industria (Sánchez 2005). No obstante, algunos de los trabajos encontrados en la literatura pueden servir de base para establecer una visión general de las concepciones, modelos y/o ideas del alumnado sobre este tema.

Uno de los primeros trabajos sobre modelos mentales de los alumnos en torno a la transformación de leche en yogur es el estudio de Díaz et al. (1996), realizado con alumnos españoles de 10 y 14 años. Este estudio empleó un cuestionario de seis preguntas relacionadas con el proceso de fermentación que pretendía indagar sobre la capacidad de los alumnos de atribuir a los microorganismos algunas transformaciones de los alimentos. El 50\% de los alumnos de 10 años consideró que el yogur se transformaba en leche sin que se produjera ningún fenómeno científico o no sabían los procesos físico-químicos implicados, mientras que un $30 \%$ consideraba que se había producido un cambio físico o químico durante la transformación. Sin embargo, el porcentaje de alumnos de 14 años que desconocía los motivos por los que se producía aumentó hasta un 69\%, mientras que los que indicaban que se había producido una transformación se redujo a un 15\%. En el mismo estudio, los alumnos debían indicar entre diferentes situaciones planteadas (infección de heridas, elaboración de pan, elaboración de vino, crecimiento de plantas, roturas de huesos, hervir líquidos y hacer yogur), cuáles tenían relación con la fermentación. Sólo el 24\% de los estudiantes de 10 años identificaron la elaboración de yogur como una fermentación, porcentaje que aumentó considerablemente $(60 \%)$ en alumnos de 14 años.

En un trabajo posterior, Simonneaux (2000) estudió las concepciones que tenían estudiantes ingleses de edades comprendidas entre 15 y 17 años sobre microbiología, centrándose en bacterias y virus, y utilizando la entrevista como instrumento de toma de datos. El 66\% consideró que las bacterias eran "bastante desagradables" y que al igual que los virus, atacaban al cuerpo humano, aunque las consideraban menos dañinas al tener, en ocasiones, un papel positivo ayudando a eliminar residuos. Así, por ejemplo, las bacterias del tracto digestivo se alimentan de la materia de desecho y por tanto, juegan un papel activo en la digestión. Este estudio también mostró la idea de los alumnos acerca de que las bacterias tienen un impacto positivo en la dieta con la mejora del valor nutricional de los alimentos (Simonneaux 2000). La formación de yogur se asoció con el desarrollo bacteriano, considerando que las bacterias eran responsables de que la leche se solidifique para transformarse en yogur. Sin embargo, algunos alumnos consideraron que este proceso también podía ocurrir en ciertas ocasiones sin la 
presencia de bacterias. Sólo un estudiante definió el yogur como un producto resultante de la fermentación de leche: "Se hace mediante la fermentación de la leche. Las bacterias atacan la materia orgánica en la leche, y por lo tanto se deshacen de la materia orgánica en ella", respuesta que muestra que este estudiante conocía el término fermentación, pero no supo explicar de forma detallada el proceso.

El trabajo de Sánchez (2005) con una amplia muestra de estudiantes colombianos de grado 8 (14 años) analizó los modelos explicativos de los alumnos sobre la acción biológica de la transformación de alimentos generados por bacterias, entre ellas la transformación de leche en yogur, en diferentes momentos de la implementación de una propuesta didáctica. Sánchez (2005) usó como instrumentos la observación, entrevistas, encuestas, test y diario del profesor. Asimismo realizó estudios de caso con dos estudiantes que resolvieron preguntas abiertas sobre microorganismos en la industria. En sus estudios de caso, antes de la unidad, Sánchez (2005) encontró dos modelos sobre la transformación de leche en yogur al preguntarles ¿Por qué si el yogurt es leche "dañada" lo podemos ingerir? Según el primer modelo, el yogur se forma cuando la leche se descompone, mientras que el segundo modelo abarca la formación de yogur a través de bacterias por un proceso denominado fermentación, sin llegarse a explicar el significado de este concepto.

La Tesis Doctoral de Moreno-Arcuri (2010) estudió los modelos mentales sobre la fermentación con alumnos mexicanos de secundaria (12-15 años) como base para comprender la respiración anaerobia. Los estudiantes mezclaron leche con bacterias y contestaron tres preguntas, ¿qué tengo?, ¿qué hice? y ¿qué pasó?, de cuyas respuestas detectó dos modelos para explicar qué ocurre cuando la leche se mezcla con bacterias. El primer modelo considera al yogur como producto de la digestión de las bacterias pero sin ser consideradas seres vivos responsables de la transformación, al tratarse de seres microscópicos (Mondelo, García y Martínez 1994). Un alumno lo expresaba de este modo: "las bacterias al comerse la leche dejan un residuo como nata y eso hace que se corte la leche asi como tipo yogur y olía como yogur natural". En el segundo modelo el yogur es también un producto procedente de la digestión de las bacterias, pero en este caso éstas se consideran seres vivos capaces de producir una descomposición del alimento: "el hongo se comió el alimento y después se descompuso", modelo también detectado en el estudio de Simonneaux (2000). Moreno-Arcuri (2010) considera este segundo modelo más avanzado que el primero, ya que sólo el 23,8 \% de los alumnos utilizaron este tipo de argumentos. No obstante, queda todavía lejos de un modelo en el que se considere la respiración anaerobia en seres vivos (las bacterias).

En un trabajo reciente, Mayerhofer (2012) investigó la construcción del modelo ser vivo por alumnos españoles de primaria. Para ello, realizó una actividad práctica consistente en la elaboración de yogur en diferentes condiciones, modificando varios parámetros en su elaboración (temperatura, composición, etc.) y posteriormente planteó cuestiones abiertas sobre el fenómeno observado. La mayoría de las respuestas indicaron que una elevada temperatura era perjudicial en la elaboración, no haciendo ninguna referencia a las bacterias, al azúcar o a la leche. Mayerhofer (2012) detectó tres modelos escolares a estas edades tempranas: a) el estudiante no es capaz de explicar el proceso, b) explica las partes que conforman el yogur indicando que las bacterias son líquidas, y c) justifica la ausencia de bacterias debidas a las altas temperaturas. Como se observa, en una escala de progreso, estos modelos deben considerarse más simples que los propuestos por Moreno-Arcuri (2010) y Simonneaux (2012), pero deben tenerse en cuenta también en la etapa de secundaria.

Aunque se han realizado algunos estudios sobre la construcción de los modelos de los estudiantes acerca de la transformación de la leche en yogur, se considera conveniente seguir avanzando en esta línea, en diferentes dimensiones. Por un lado, desde el punto de vista 
metodológico sería conveniente utilizar además de las explicaciones verbales el análisis de dibujos sobre el proceso, que no se han demandado en los estudios anteriores. Por otro lado, no se han encontrado trabajos realizados en nuestro país en el contexto de la educación secundaria obligatoria.

\section{Objetivos de la investigación}

Este trabajo se corresponde con la fase inicial para la elaboración de una propuesta de enseñanza centrada en la modelización del cambio químico en el contexto de la transformación de la leche en yogur. En consecuencia, los objetivos que se pretenden en esta investigación son:

a) Explorar las explicaciones de estudiantes de secundaria sobre la transformación de leche en yogur.

b) Identificar posibles modelos mentales que estén en la base de las explicaciones aportadas por los estudiantes.

\section{Metodología}

El enfoque metodológico empleado en este estudio es de tipo cualitativo (Atkins y Wallace 2012), dado que para conocer los modelos mentales de los estudiantes se utilizan tareas abiertas. Todas las respuestas fueron analizadas por los tres miembros del equipo investigador elaborando sistemas de categorización a partir de dichas respuestas (Dey 2005).

\section{Participantes}

El estudio se realizó con una muestra de 153 estudiantes de edades entre 13 y 15 años que pertenecían a tres institutos de secundaria de Málaga. El 55\% de los participantes eran chicas, y el $45 \%$ chicos. Todos ellos cursaban la asignatura de Física y Química, 78 en $2^{\circ}$ de ESO y 75 en $3^{\circ}$ de ESO. Se trata de alumnos correspondientes a los dos últimos cursos en los que las ciencias son obligatorias, pudiendo representar, con ello, las ideas de la gran mayoría de la población de estas edades sobre la cuestión abordada.

\section{Instrumentos de recogida de datos}

Para elaborar el instrumento de recogida de datos se tuvo en cuenta por un lado la literatura acerca de las concepciones de los estudiantes sobre este fenómeno, ya descritas, lo que puso de manifiesto la importancia de abordar la exploración de las ideas y modelos mentales de los alumnos desde diferentes perspectivas, demandando al alumnado tanto sus explicaciones verbales como sus dibujos.

Teniendo en cuenta las consideraciones expuestas en el apartado "Modelo escolar sobre la fermentación láctica", y para conseguir hacer aflorar los modelos mentales de los alumnos sobre la transformación de leche en yogur se diseñaron dos tareas, que los estudiantes respondieron de forma individual. La Tabla 2 recoge los enunciados y objetivos de dichas tareas. 
Tabla 2. Tareas propuestas

\begin{tabular}{|c|c|c|}
\hline Tarea & Enunciado & Objetivo de la tarea \\
\hline 1 & ¿Cómo crees que la leche se transforma en yogur? & \begin{tabular}{lcrr} 
Identificar & \multicolumn{2}{c}{ analizar } & los \\
modelos de & los & estudiantes \\
centrándose & & en & la \\
transformación. & &
\end{tabular} \\
\hline 2 & $\begin{array}{l}\text { a) La leche se transforma en yogur por un proceso que se denomina } \\
\text { fermentación. En este proceso son importantes dos sustancias, azúcar } \\
\text { (lactosa) y ácido láctico, e intervienen unas bacterias que son seres vivos } \\
\text { microscópicos. Suponiendo que dispusieses de unas gafas muy } \\
\text { potentes, con las que pudieses ver extraordinariamente ampliadas las } \\
\text { MOLÉCULAS de estas dos sustancias y a las BACTERIAS, ¿cómo } \\
\text { crees que las verías en la leche?, ¿y en el yogur? Dibuja cómo te } \\
\text { imaginas la leche y el yogur y explica los dibujos. } \\
\text { b) Suponiendo que continúas con las mismas gafas. Haz una } \\
\text { representación del proceso de transformación de la leche en yogur } \\
\text { (fermentación), teniendo en cuenta los componentes más importantes } \\
\text { en este proceso: azúcar (lactosa), ácido láctico y bacterias. Por favor, } \\
\text { explica tu representación. }\end{array}$ & $\begin{array}{l}\text { Analizar los modelos mentales } \\
\text { en el ámbito micro y } \\
\text { submicroscópico. }\end{array}$ \\
\hline
\end{tabular}

La redacción de la primera tarea no demandaba a los estudiantes utilizar conocimientos relativos a las sustancias implicadas o a las bacterias en los ámbitos micro y submicroscópico; lo cual no quiere decir que no lo pudiesen indicar en sus respuestas. Por el contrario, la segunda tarea solicitaba específicamente que incluyeran ideas relacionadas con los ámbitos micro y submicroscópico.

Los estudiantes resolvieron la primera tarea de forma independiente, facilitándose la segunda tras finalizarla, disponiendo en total de 30 minutos. La recogida de datos se efectuó durante el mes de mayo de 2016 para asegurar que ya habían cursado la gran mayoría de los contenidos de las asignaturas de ciencias correspondientes a cada uno de los cursos, referidas al ámbito de las transformaciones químicas. Se efectuó en presencia de la investigadora (primera autora del artículo), cuya labor se limitó a explicar las tareas y a responder las dudas que pudiesen surgir. La investigadora no interfirió en ningún momento en las respuestas de los alumnos.

\section{Análisis de datos}

Se llevó a cabo un análisis pormenorizado de las respuestas de los estudiantes para cada tarea, identificando en ellas posibles modelos mentales y estableciendo a partir de ellos un esquema de progreso. Para ello, los tres miembros del equipo de investigación (autores de este trabajo) realizaron de forma individual una lectura de las respuestas, y mediante un proceso inductivo e iterativo emergieron las diferentes categorías. En el caso de las respuestas en las que se encontraron discrepancias, se trabajó de forma conjunta para dilucidar las categorizaciones.

Para poder categorizar las respuestas se analizaron los dibujos y explicaciones que ofrecían los estudiantes de forma conjunta, a partir de los cuales se han podido identificar los posibles modelos que subyacen. Se entiende que el modelo es una representación del fenómeno que los alumnos pueden verbalizar por diferentes lenguajes (gráficos, verbal, etc.). En este estudio se considera que un modelo mental sobre la transformación de leche en yogur debe tener dos componentes: a) la presencia o no de las bacterias y su papel en este proceso y b) el tipo de trasformación que se produce. La figura 1 se utiliza como ejemplo para ilustrar cómo se llevó a cabo este análisis. 

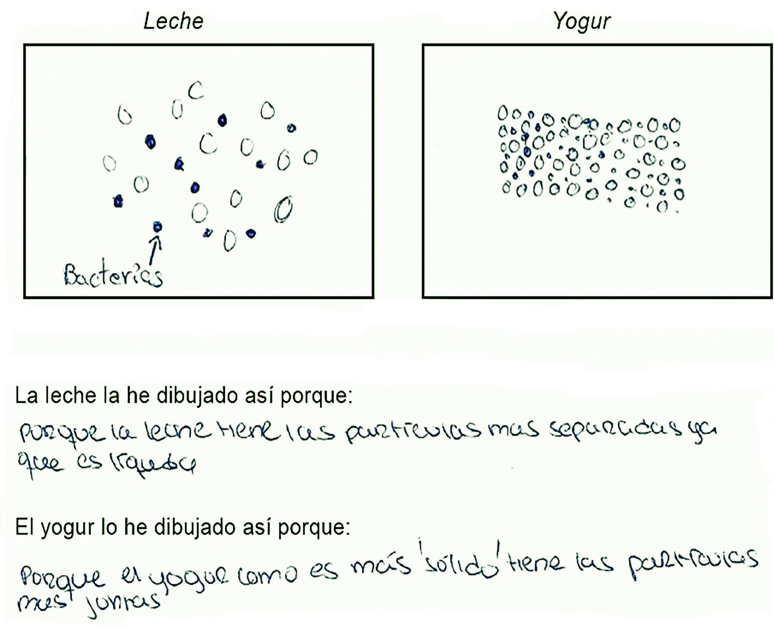

Figura 1. Ejemplo de respuesta de la tarea 2a

En los dibujos se aprecia cómo esta alumna representa la leche y el yogur con dos componentes (moléculas de leche y bacterias), siendo la única diferencia apreciable entre ambos, la separación existente entre las moléculas, que se encuentran más juntas en el yogur. Se deduce, por tanto, que esta alumna no otorga ningún papel a las bacterias en el proceso, y que el modelo mental que subyace es un proceso físico similar a un cambio de estado.

Cabe destacar que los estudiantes sólo emplearon representaciones gráficas en la tarea 2 , respondiendo la tarea 1 de forma verbal. Para la identificación de los componentes en los dibujos, los estudiantes emplearon tres tipologías: dibujos reales, figuras geométricas y un modelo de esferas (figura 2), tal y como se hace en las reacciones químicas para esquematizar a átomos y moléculas.

a) Figuras geométricas

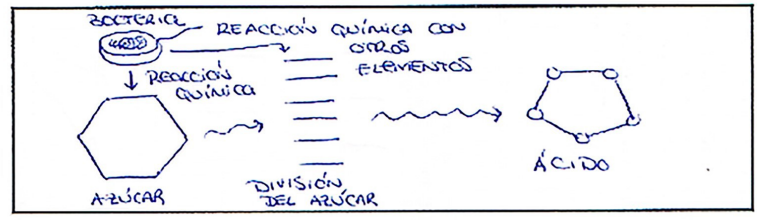

b) Dibujos reales

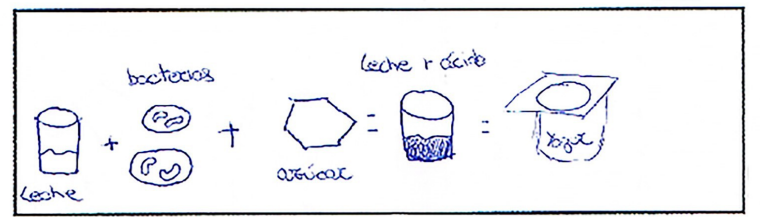

c) Esferas
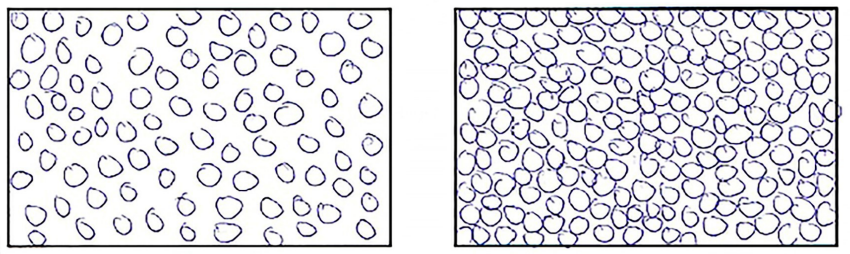

Figura 2. Modelos utilizados para representar la transformación de la leche en yogur usando a) figuras geométricas, b) dibujos reales, c) esferas. 
Una vez analizadas las respuestas de los estudiantes e identificados, en su caso, los modelos se llevó a cabo la prueba estadística de chi cuadrado, con objeto de analizar posibles diferencias entre categorías de respuestas de los alumnos de $2^{\circ}$ y $3^{\circ}$ de ESO en cada tarea.

\section{Resultados y discusión}

En esta sección se analizan las dos tareas de forma conjunta, ya que de ambas se pueden deducir modelos mentales similares. La tabla 3 recoge los siete modelos identificados en nuestro estudio indicando también otros trabajos que previamente los habían descritos. Todos ellos aparecen en los dos cursos, lo que parece indicar que están extendidos en la muestra estudiada. Además, cuatro de ellos se detectan en los dos niveles (macro y micro/submicroscópico). Los modelos identificados entienden la transformación de leche en yogur como: 1) un proceso mecánico, 2) un proceso físico semejante a un cambio de estado, 3) un aumento en el número de bacterias, 4) una mezcla de componentes, 5) un proceso en el que intervienen bacterias sin un papel activo, 6) un proceso donde las bacterias tienen un papel activo, y 7) una fermentación. Estos modelos se han ordenado de menor a mayor grado de proximidad con el modelo escolar empleando dos criterios: a) se considera que los modelos que mencionan bacterias son más avanzados que los que no lo hacen, y b) dentro de aquellos, los modelos se ordenan según el papel que otorgan a las bacterias en el proceso de transformación de leche en yogur, es decir, si las bacterias interactúan o no con otros componentes de la leche y, en caso afirmativo qué tipo de interacción se produce.

Como se observa en la tarea 1 , asociada aunque no de forma exclusiva al ámbito macroscópico, se identifican cinco modelos $(1,2,4,5$ y 7$)$, mientras que en la tarea 2 relativa al ámbito micro/submicroscópico se encontraron seis modelos (todos menos el modelo 1).

Destaca en ambas tareas el elevado porcentaje de estudiantes de los dos cursos que no las resuelven, en torno al $25 \%$ en la tarea 1 y al $54 \%$ en la tarea 2 (tabla 3). Al recogerlas, la investigadora preguntó por este hecho, indicándole los estudiantes que desconocían la respuesta, muestra de la dificultad que supone para ellos representar un fenómeno especialmente en el ámbito submicroscópico.

Otro aspecto a destacar es que en prácticamente todas las categorías encontradas en las dos tareas, los porcentajes de respuestas son muy similares en ambos cursos, mostrando la prueba estadística de chi cuadrado que no existen diferencias significativas entre las ideas manifestadas por los alumnos de $2^{\circ}$ y $3^{\circ}$ de ESO.

Si realizamos un análisis detallado de los resultados, se observa que el modelo predominante de los estudiantes de $2^{\circ}$ y $3^{\circ}$ de ESO en ambos niveles de organización de la materia es un modelo donde no intervienen bacterias y que no implica una transformación, sino más bien un cambio de estado que no altera la naturaleza del producto (modelo 2). Díaz et al. (1996) y Moreno-Arcuri (2010) también encontraron este modelo. Incluso algunos alumnos explicaron esta transformación de estado líquido (leche) a estado sólido (yogur) empleando términos de cambios de estado: "solidificando la leche" (Estudiante de $2^{\circ}$ de ESO, tarea 1).

En el ámbito macroscópico, la segunda categoría en cuanto a su presencia, es aquella en las que el proceso se produce a través de una transformación "dejando que se fermente" (estudiante de $3^{\circ}$ ESO), pero sin explicar el proceso (modelo 7), un modelo ya identificado por Simonneaux (2000) y Sánchez (2005). Sin embargo, a pesar de tratarse del modelo más cercano al modelo escolar, tiene una escasa presencia en el ámbito micro/submicroscópico. 
Tabla 3. Modelos mentales de la transformación de leche en yogur en los ámbitos macro y micro/submicroscópico identificados.

\begin{tabular}{|c|c|c|c|c|c|c|c|c|c|c|}
\hline & \multirow[b]{3}{*}{ Modelo } & \multirow[b]{3}{*}{$\begin{array}{c}\text { Estudios que lo } \\
\text { identifican }\end{array}$} & \multicolumn{4}{|c|}{$\begin{array}{l}\text { Tarea } 1 \text { (Ámbito } \\
\text { macroscópico) }\end{array}$} & \multicolumn{4}{|c|}{$\begin{array}{l}\text { Tarea } 2 \text { (ámbito micro y } \\
\text { submicroscópico) }\end{array}$} \\
\hline & & & \multicolumn{2}{|c|}{ Frecuencia } & \multicolumn{2}{|c|}{$\begin{array}{c}\text { Porcentaje } \\
(\%)\end{array}$} & \multicolumn{2}{|c|}{ Frecuencia } & \multicolumn{2}{|c|}{$\begin{array}{c}\text { Porcentaje } \\
(\%)\end{array}$} \\
\hline & & & $\begin{array}{c}2^{\circ} \\
\text { ESO }\end{array}$ & $\begin{array}{c}3^{\circ} \\
\text { ESO }\end{array}$ & $\begin{array}{c}2^{\circ} \\
\text { ESO }\end{array}$ & $\begin{array}{c}3^{\circ} \\
\text { ESO }\end{array}$ & $\begin{array}{c}2^{\circ} \\
\text { ESO }\end{array}$ & $\begin{array}{c}3^{\circ} \\
\text { ESO }\end{array}$ & $\begin{array}{c}2^{\circ} \\
\text { ESO }\end{array}$ & $\begin{array}{c}3^{\circ} \\
\mathrm{ESO}\end{array}$ \\
\hline \multirow[t]{2}{*}{$\begin{array}{l}\text { No } \\
\text { mencionan } \\
\text { las bacterias }\end{array}$} & $\begin{array}{l}\text { A través de procesos mecánicos } \\
\text { (en una fábrica o con máquinas) } \\
\text { (Modelo 1) }\end{array}$ & & 4 & 4 & 5.1 & 5.3 & 0 & 0 & 0 & 0 \\
\hline & $\begin{array}{l}\text { La transformación es entendida } \\
\text { como un proceso físico muy } \\
\text { semejante a un cambio de estado } \\
\text { (Modelo 2) }\end{array}$ & $\begin{array}{l}\text { Díaz et al. (1996) } \\
\text { Moreno-Arcuri (2010) }\end{array}$ & 21 & 22 & 26.9 & 29.3 & 11 & 9 & 14.1 & 12.2 \\
\hline \multirow[t]{5}{*}{$\begin{array}{l}\text { Mencionan } \\
\text { las bacterias }\end{array}$} & $\begin{array}{l}\text { El proceso de fermentación } \\
\text { implica un aumento en el número } \\
\text { de bacterias (Modelo } 3 \text { ) }\end{array}$ & & 0 & 0 & 0 & 0 & 2 & 1 & 2.6 & 1.4 \\
\hline & $\begin{array}{l}\text { El proceso se muestra como una } \\
\text { mezcla macroscópica de leche, } \\
\text { azúcar, ácido láctico y bacterias } \\
\text { (Modelo 4) }\end{array}$ & & 7 & 9 & 9.0 & 12.0 & 11 & 10 & 14.1 & 13.5 \\
\hline & $\begin{array}{l}\text { La transformación entendida como } \\
\text { un proceso físico en el que } \\
\text { aparecen las bacterias, sin que éstas } \\
\text { interaccionen con las demás } \\
\text { moléculas (Modelo 5) }\end{array}$ & Simonneaux (2000) & 8 & 4 & 10.3 & 5.3 & 3 & 3 & 3.8 & 4.1 \\
\hline & $\begin{array}{l}\text { Bacterias como aglutinante de otras } \\
\text { moléculas. Las bacterias tienen un } \\
\text { papel activo que consiste en juntar } \\
\text { las moléculas que están separadas } \\
\text { en la leche (Modelo 6) }\end{array}$ & & 0 & 0 & 0 & 0 & 6 & 8 & 7.7 & 10.8 \\
\hline & $\begin{array}{l}\text { Implica un proceso en el que la } \\
\text { leche se fermenta cuando se le } \\
\text { añade bacterias, pero sin indicar } \\
\text { que la fermentación es un proceso } \\
\text { químico que transcurre a través de } \\
\text { una reacción química (Modelo } 7 \text { ) }\end{array}$ & $\begin{array}{l}\text { Simonneaux (2000) } \\
\text { Sánchez (2005) }\end{array}$ & 18 & 17 & 23.1 & 22.7 & 3 & 3 & 3.8 & 4.1 \\
\hline No explican & $\begin{array}{l}\text { No se explica el proceso / no se } \\
\text { entiende el proceso }\end{array}$ & & 20 & 19 & 25.6 & 25.3 & 42 & 40 & 53.8 & 54.1 \\
\hline
\end{tabular}


Cabe resaltar el porcentaje de estudiantes que emplea el término bacterias en el nivel macroscópico (un $10 \%$ en $2^{\circ}$ de ESO y un $5 \%$ en $3^{\circ}$ de ESO), lo que no supone que este término no sea conocido por el resto de alumnos. De hecho, en muchos casos probablemente está implícito en este ámbito al referirse a la fermentación en el modelo más adecuado o en otros, ya que las utilizan en el ámbito microscópico: "El yogur tiene bacterias benignas" (Estudiante de $2^{\circ}$ de ESO, tarea 1). "La leche la mezclan con bacterias para formar yogur" (Estudiante de $3^{\circ}$ de ESO, tarea 1).

Las respuestas con menor frecuencia en el nivel macroscópico en ambos cursos se refieren a que la transformación implica procesos mecánicos: "se produce a través de máquinas" (Estudiante de $3^{\circ}$ de ESO), "en una fábrica" (Estudiante de $2^{\circ}$ de ESO), el modelo más simple y que desaparece en el ámbito submicroscópico. Tiene interés analizar cómo entienden los estudiantes la transformación de leche en yogur a nivel submicroscópico (tarea 2) en cada uno de los modelos:

Modelo 2: Es un modelo simple, ya que no intervienen las bacterias en la transformación y ésta es entendida como un proceso físico semejante a un cambio de estado (de líquido a sólido). Se trata del segundo modelo mayoritario encontrado en ambos cursos, utilizado por un $14.1 \%$ de los alumnos de $2^{\circ}$ de ESO y un $12.2 \%$ en $3^{\circ}$ de ESO. La figura 3 muestra las respuestas de dos estudiantes (uno de cada curso) categorizadas dentro de este modelo.

\section{FIGURA 3A}
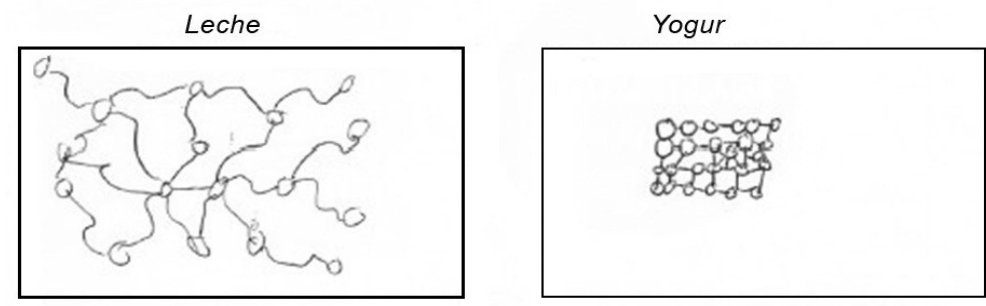

En la leche las he dibujado así porque:

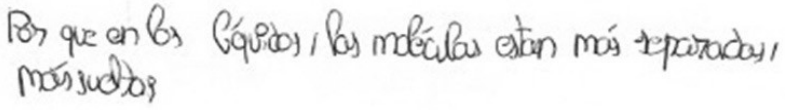

En el yogur he dibujado así porque:

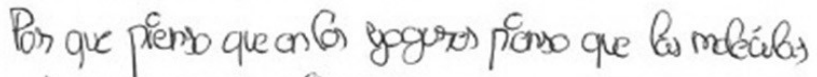

$$
\begin{aligned}
& \text { esán cispuestas márjuntos }
\end{aligned}
$$

\section{FIGURA 3B}

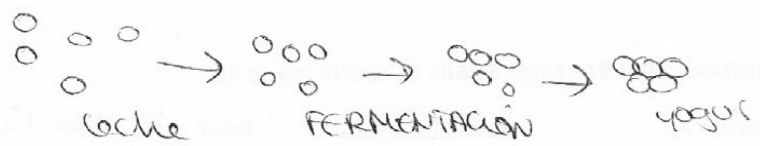

Por favor explica tu representación:

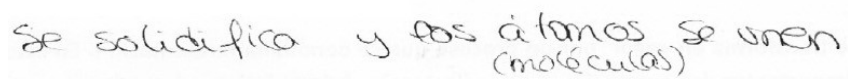

Figura 3. Ejemplos del modelo 2 de un estudiante de a) $2^{\circ}$ ESO y b) $3^{\circ}$ ESO 
Los estudiantes que muestran este modelo habían respondido en el mismo sentido de cambio de estado en la tarea 1 sobre las diferencias entre leche y yogur en términos macroscópicos. Este modelo puede considerarse, como una manifestación de una característica del pensamiento cotidiano de los estudiantes, en el sentido de que los procesos en el ámbito submicroscópico ocurren tal y como se observan en el macroscópico (Driver 1989).

Modelo 3: Es el primer modelo que alude a las bacterias en la transformación. Los estudiantes indican que el proceso de fermentación implica un aumento en el número de bacterias (figura 4). Se trata del modelo menos empleado (en torno al $3 \%$ en $2^{\circ}$ de ESO y $1.4 \%$ en $3^{\circ}$ de ESO).

FIGURA 4A
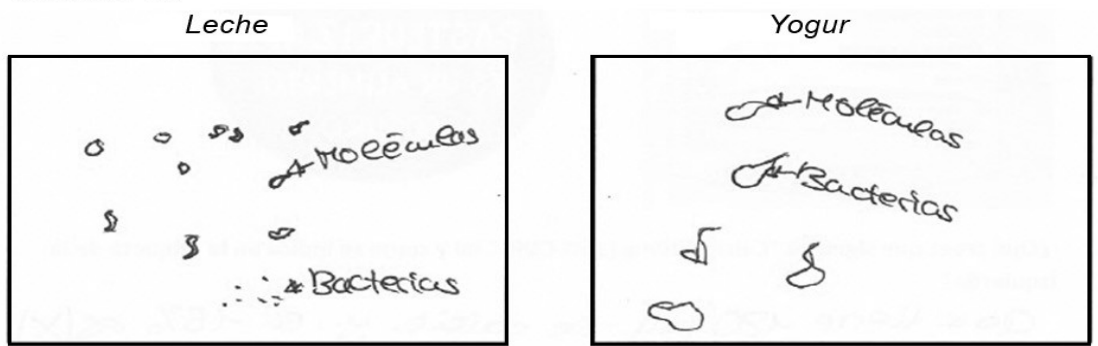

En la leche las he dibujado así porque:

Plenso gue pas badotias sen más pequeñas que

eces moécueas.

En el yogur las he dibujado así porque:

Horgoe si estä eermentado eas bacterias

secan már grandes. y habrá más

\section{FIGURA 4B}
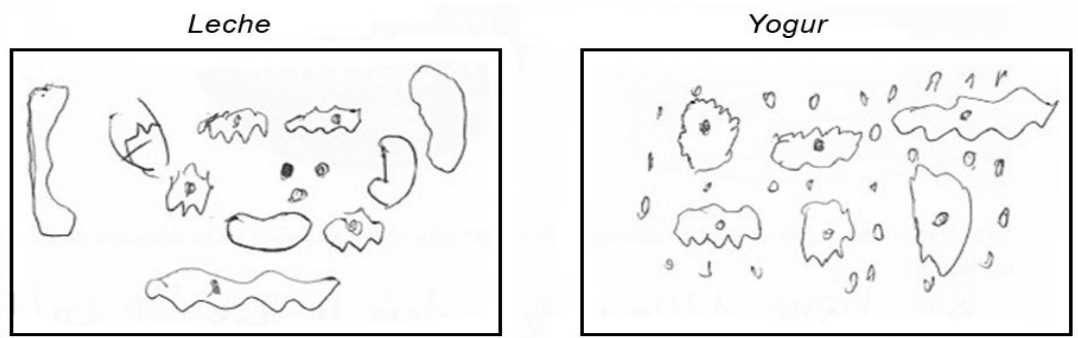

En la leche las he dibujado asi porque:
Porque me la imagino así.

En el yogur las he dibujado así porque:

$$
\begin{aligned}
& \text { Porque creo que tiene más bactorius que la } \\
& \text { leche ig me lo imagina asi. }
\end{aligned}
$$

Figura 4. Ejemplos del modelo 3 de un estudiante de a) $2^{\circ}$ ESO y b) $3^{\circ} \mathrm{ESO}$

Modelo 4: El proceso se entiende como una mezcla macroscópica de leche, azúcar, ácido láctico y bacterias. Aunque este modelo considera a las bacterias, los estudiantes no se muestran capaces de expresarlo en términos microscópicos, sino como dibujos macroscópicos, como 
puede observarse en los ejemplos de la figura 5. Se trata, no obstante, del modelo mayoritario, empleado por el $14.1 \%$ y $13.5 \%$ de los alumnos de $2^{\circ}$ y $3^{\circ} \mathrm{ESO}$, respectivamente en la tarea 2.
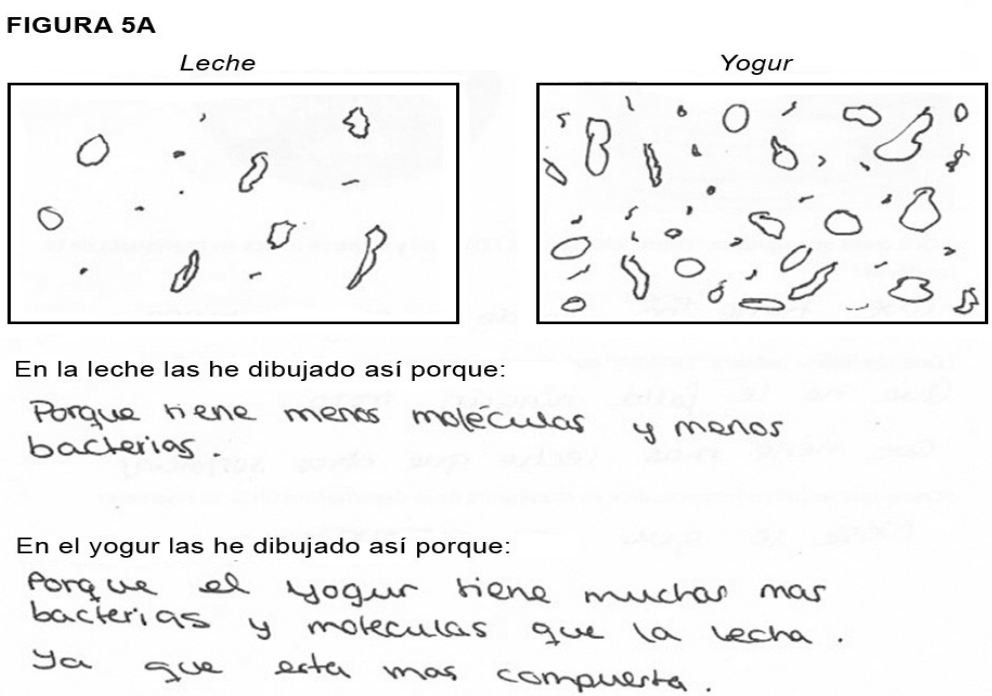

En la leche las he dibujado así porque:

Porque hiene menos moléculas y menos bacterias.

En el yogur las he dibujado asi porque:

Porgue el yogur tiene muchar mas

bacterias y moleculas que la lecha.

Ya ave erta mas compuerta.

\section{FIGURA 5B}

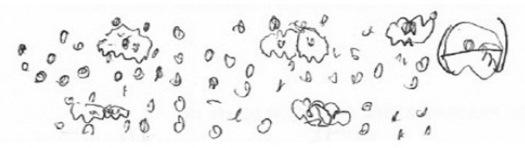

Por favor, explica tu representación:

Porque me imagino que hay muchas sostancias mezclandose.

Figura 5. Ejemplos del modelo 4 de un estudiante de a) $2^{\circ}$ ESO y b) $3^{\circ}$ ESO

Modelo 5: La transformación del yogur se considera un proceso físico en las que aparecen las bacterias pero sin interaccionar con las moléculas de la leche (figura 6). Se trata de un modelo considerado solamente por el $4 \%$ de los alumnos de cada curso a nivel microscópico, también detectado por Simonneaux (2000).
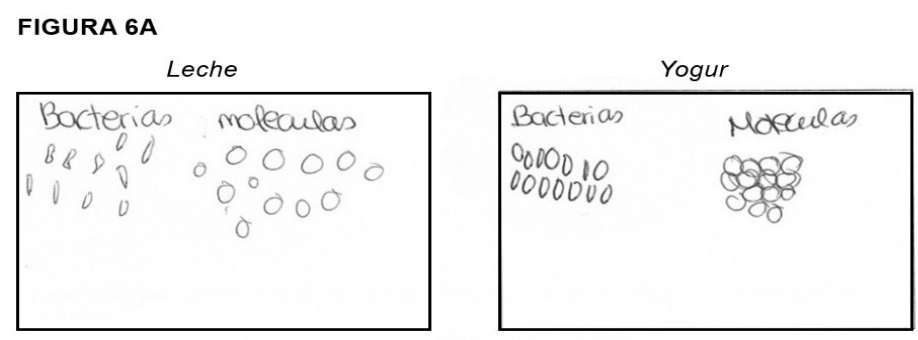

\section{FIGURA 6B}
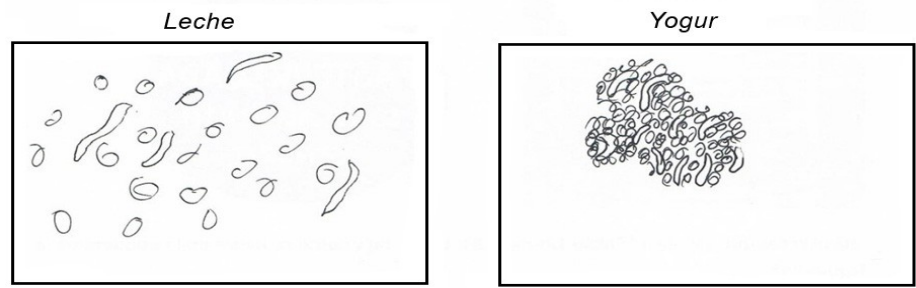

Figura 6. Ejemplos del modelo 5 realizado por un estudiante de a) $2^{\circ} \mathrm{ESO}$ y b) $3^{\circ} \mathrm{ESO}$ 
Este modelo puede considerarse muy similar al modelo 2, ya que el único avance observado en el mismo es que los estudiantes incorporan en sus dibujos y explicaciones a las bacterias, puesto que así se le indicaba en la tarea, pero sin que éstas tengan un papel realmente o intervengan en el proceso de transformación de la leche en yogur.

Modelo 6: Se considera a las bacterias con un papel activo como aglutinante de las moléculas de la leche. La figura 7 ilustra dos ejemplos donde los dibujos muestran cómo los componentes de la leche y las bacterias se encuentran inicialmente separados, y en el yogur las bacterias van uniendo los componentes de la leche. Este modelo fue también identificado por Simonneaux (2000).

FIGURA 7A

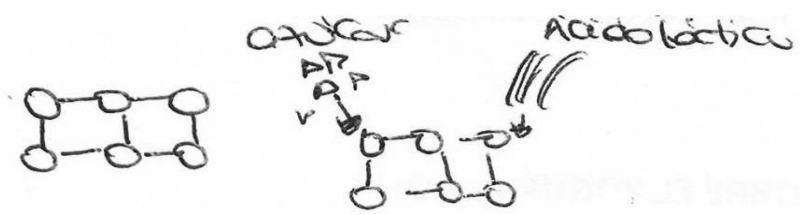

FIGURA 7B
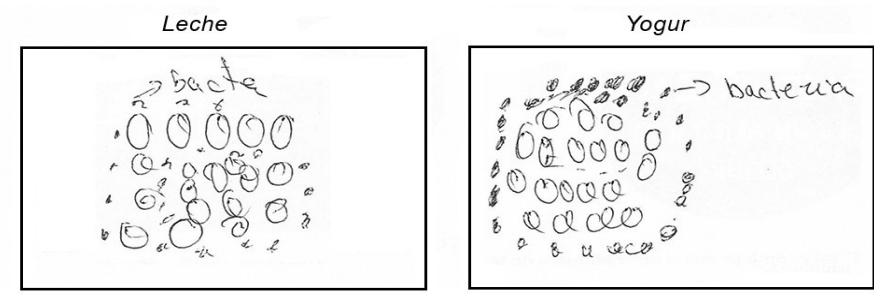

Figura 7. Ejemplos del modelo 6 realizadas por un estudiante de a) $2^{\circ}$ ESO y b) $3^{\circ}$ ESO

Modelo 7: Implica un proceso en el que la leche se fermenta al añadirle bacterias, pero sin indicar que se trata de un proceso químico que transcurre a través de una reacción bioquímica. La figura 8 recoge algunos ejemplos encontrados.

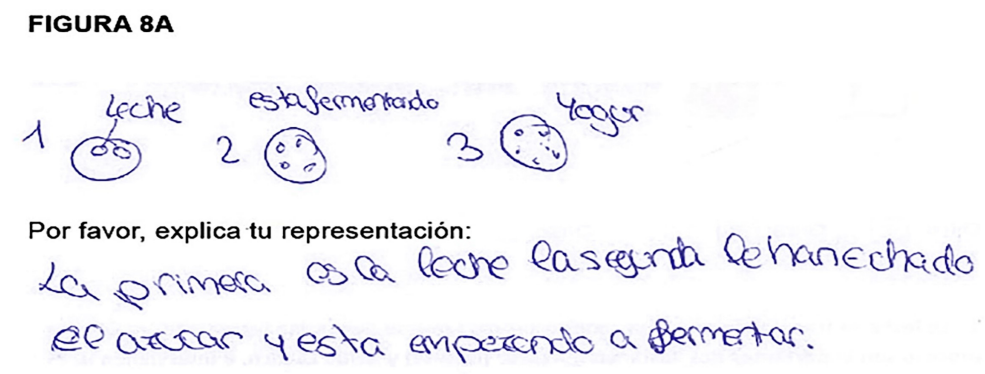

FIGURA 8B

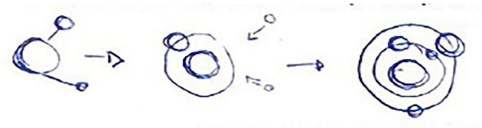

Por favor, explica tu representación:

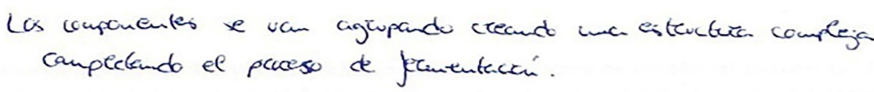

Figura 8. Ejemplos del modelo 7 de un estudiante de a) $2^{\circ}$ ESO y b) $3^{\circ}$ ESO 
Se trata del modelo más avanzado identificado en esta muestra de estudiantes a nivel submicroscópico, aún muy alejado del modelo escolar, donde la transformación de la leche en yogur implica un cambio químico que se produce debido a la acción de las bacterias.

Para verificar si existen diferencias significativas entre ambos cursos se realizaron dos análisis estadísticos. Por un lado, la prueba de chi cuadrado para determinar posibles diferencias entre modelos que mencionan bacterias y los que no lo hacen y, por otro lado, se estudiaron posibles diferencias entre los modelos que mencionan bacterias. Ambos análisis no mostraron diferencias estadísticamente significativas, lo que pone de manifiesto que los modelos mentales de la transformación de leche en yogur son similares en estudiantes de $2^{\circ}$ y $3^{\circ} \mathrm{ESO}$, sin que se aprecien evidencias de progresión en los mismos.

\section{Consideraciones e implicaciones educativas}

En la ciencia escolar, la transformación de la leche en yogur es entendida como un proceso bioquímico en el que intervienen seres vivos (bacterias) que transforman las moléculas de lactosa de la leche en ácido láctico. Sin embargo, los resultados de esta investigación muestran que los estudiantes de $2^{\circ}$ y $3^{\circ}$ de ESO presentan grandes dificultades para explicar esta transformación en los ámbitos macro y submicroscópico.

A pesar de que son capaces de proponer hasta siete modelos diferentes, todos ellos están aún muy alejados del modelo escolar, al considerar la transformación láctica como un proceso mecánico, un cambio de estado, un aumento del número de componentes, una mezcla, un proceso en el que aparecen bacterias con o sin papel activo o una fermentación. Tampoco aparecen ideas relativas a las bacterias como seres vivos. Solo en algunos de los modelos, especialmente en el modelo 3, aparecen referencias al aumento del número de bacterias durante el proceso; aunque los estudiantes no siempre lo indican de forma explícita. Esto podría ser indicativo de la idea de que como seres vivos pueden reproducirse. No obstante, también parece que ocurre con la materia inerte. Estas ideas aparecen confusas en los dibujos de los alumnos y necesitan ser objeto de atención didáctica.

Algunos de estos modelos han sido ya identificados en estudios previos (Díaz et al. 1996; Simonneaux 2000; Sánchez 2005; Moreno-Arcuri 2010). Sin embargo, cuatro de los modelos identificados: la fermentación es un proceso mecánico (modelo 1), implica un aumento en el número de bacterias (modelo 3), consiste en una mezcla macroscópica (modelo 4) y las bacterias como aglutinante de otras moléculas con un papel activo que consiste en juntar las moléculas que están separadas en la leche (modelo 6), deben considerarse una aportación de este trabajo, al no haber sido identificados en ninguno de los estudios anteriores en secundaria. Otro aspecto a resaltar es que parece haberse superado los modelos más simples habituales en la etapa de primaria (Mayerhofer 2012) (las bacterias son líquidas o ausencia de bacterias a altas temperaturas), que no fueron detectados en nuestro estudio.

Los modelos explicitados por los alumnos parecen plantear un desafío para hacerlos progresar hacia el modelo escolar, por lo que debemos recurrir a nuevas estrategias didácticas para avanzar en su aprendizaje. En este sentido, la elaboración de yogur en el aula podría constituir un contexto cotidiano adecuado para abordar la modelización. Por otra parte, la enseñanza de las ciencias basada en la indagación aplicada a la elaboración de yogur podría favorecer una mayor comprensión del proceso. Es por ello, que para completar el estudio, se pretenda, teniendo en cuanta los resultados obtenidos y la literatura existente, elaborar una propuesta didáctica para secundaria centrada en este tema integrando enfoques de enseñanza en contexto, modelización e indagación. Para avanzar en este sentido, se está utilizando un esquema de diseño que contempla cuatro dimensiones: 
1) Trabajar en la progresión de los modelos con idea de contemplar los diversos modelos iniciales que los estudiantes pueden tener sobre la fermentación, hasta llegar al modelo escolar.

2) Plantear prácticas científicas de modelización, tales como representar fenómenos, objetos o procesos mediante imágenes y simulaciones; aplicar modelos en situaciones de indagación, por ejemplo, lo que le ocurre a la leche cuando se le agrega un ácido, en general, como un paso previo a la elaboración de yogur; implicar al alumnado en la generación, discusión y consenso de modelos, etc.

3) Plantear tareas centradas en el contexto (información sobre el yogur, prácticas de indagación en la elaboración de yogur, etc.) para ayudar al desarrollo de los modelos y a las prácticas de modelización.

4) Tomar decisiones en el proceso de enseñanza-aprendizaje acordes con las finalidades de modelización y contextualización: tareas de enseñanza que se utilizarán, secuenciación de las mismas, estrategias didácticas, etc.

\section{Agradecimientos}

Este trabajo forma parte del Proyecto de I+D de Excelencia "Desarrollo y evaluación de competencias científicas mediante enfoques de enseñanza en contexto y de modelización. Estudios de caso" (EDU2013-41952P) financiado por el Ministerio de Economía y Competitividad.

\section{Referencias}

Acher A. (2014) Cómo facilitar la modelización científica en el aula. Tecné, Episteme y Didaxis: Revista de la Facultad de Ciencia y Tecnología 36, 63-75.

Ainsworth S., Prain V., Tytler, R. (2011) Drawing to learn in Science. Science 333, 1096-1097.

Andree M. (2005) Ways of using "everyday life" in the science classroom. In K. Boersma, M. Goedhart, O. de Jong y M. Eijkelhof, (eds.) Research and the Quality of Science Education (pp. 107-119). Dordrecht: Springer.

Aragón M.M. (2012) Aportaciones de la enseñanz̧a con analogias al desarrollo del pensamiento modelizador de los alumnos acerca del cambio químico. Tesis Doctoral. Cádiz: Universidad de Cádiz.

Atkins L., Wallace, S. (2012) Qualitative Research in Education. London: Sage Publications Ld.

Balaguer L., García R., Mantero, M.A. (2006) Yogur “versus” yogur pasteurizado. Alambique: Didáctica de las Cencias Experimentales 48, 119-123.

Caamaño A. (2011) Contextualización, indagación y modelización Tres enfoques para el aprendizaje de la competencia científica en las clases de química. Aula de Innovación Educativa 207, 17-21.

Chi M., Slotta J., Leeuw, N. (1994) From things to processes: A theory of conceptual change for learning science concepts. Learning and Instruction 4, 27-43.

Clement J.J. (2000) Model based learning as a key research area for science education. International Journal of Science Education 22(9), 1041-1053.

Coll R.K., Treagust, D.F. (2003) Learners' mental models of metallic bonding: A crossage study. Science Education 87(5), 685-707.

Dey I. (2005) Qualitative data analysis. A user-friendly guide for social scientific. London: Taylor \& Francis. 
Díaz R., López R., García A., Abuín G., Nogueira E., Garcia J.A. (1996) ¿Son los alumnos capaces de atribuir a los microorganismos algunas transformaciones de los alimentos? Enseñanza de las Ciencias 14(2), 143-153.

Driver R. (1989) Un enfoque constructivista para el desarrollo del currículo en ciencias. Enseñanza de las Ciencias 6(2), 109-120.

Franco-Mariscal A.J. (2015) Exploring the Everyday Context of Chemical Elements: Discovering the Elements of Car Components. Journal of Chemical Education 92(10), 1672-1677.

Furió C., Domínguez M.C. (2007) Problemas históricos y dificultades de los estudiantes en la conceptualización de sustancia y compuesto químico. Enseñanza de las Ciencias 25(2), 241-258.

Gilbert J.K., Boulter C., Rutheford M. (1998) Models in explanations, Part 1: Horses for courses? International Journal of Science Education 20(1), 83-97.

Girón J. (2017) Estudios sobre el tratamiento de la publicidad de productos alimentarios en la enseñanza de las ciencias. Tesis Doctoral. Málaga: Universidad de Málaga.

Gómez V., Gavidia V. (2015) Describir y dibujar en ciencias. La importancia del dibujo en las representaciones mentales del alumnado. Revista Eureka sobre Enseñanza y Divulgación de las Ciencias 12(3), 441-455.

Gómez-Galindo A., Sanmartí N., Pujol, R. (2007). Fundamentación teórica y Diseño de una unidad didáctica para la enseñanza del modelo ser vivo en la escuela primaria. Enseñanza de las Ciencias 25(3), 325-340.

Hafner R., Stewart J. (1995) Revising explanatory models to accommodate anomalous genetic phenomena: Problem solving in the "context of discovery". Science Education 79(2), 111-146.

Jiménez-Liso M.R., López-Gay R., Márquez, M.M. (2010) Química y cocina: del contexto a la construcción de modelos. Alambique: Didáctica de las Ciencias Experimentales 65, 33-44.

Justi R., Gilbert J.K. (2002) Modelling teachers' views on the nature of modelling, and implications for the education of modellers. International Journal of Science Education 24(4), 369-387.

Mayerhofer N. (2012) La construcción del modelo ser vivo por alumnos de primaria: una propuesta de análisis basada en una progresión de aprendizaje. Tesis Doctoral. Barcelona: Universidad Autónoma de Barcelona.

MEC, Ministerio de Educación y Ciencia (2014) Real Decreto 126/2014, de 28 de febrero, por el que se establece el currículo básico de Educación Primaria (BOE núm. 52, 1 de Marzo de 2014).

MEC, Ministerio de Educación y Ciencia (2015) Real Decreto 1105/2014, de 26 de diciembre, por el que se establece el currículo básico de la Educación Secundaria Obligatoria y del Bachillerato (BOE núm. 3, 3 de Enero de 2015).

Messens W., De Vuyst L. (2002) Inhibitory substances produced by Lactobacilli isolated from souroughs-a review. International Journal of Food Microbiology 72, 31-43.

Mondelo A., García S., Martínez C. (1994) Materia inerte/Materia viva. ¿'Tienen ambas la misma constitución atómica? Enseñanza de las Ciencias 12(2), 226-233. 
Moreno-Arcuri G. (2010) Construcción de modelos escolares, en un g rupo de primero de secundaria acerca de la fermentación. Tesis Doctoral. México, D.F.: Universidad Pedagógica Nacional.

Muñoz-Campos V., Blanco-López A., Franco-Mariscal, A.J. (2015) La elaboración de yogur como contexto para el aprendizaje de la reacción química mediante modelización. En P. Membiela, N. Casado y M.I. Cebreiros (eds.), La enseñanza de las ciencias: desafíos y perspectivas (pp. 265-269). Ourense: Educación Editora.

Norman D. A. (1983) Some observations on mental models. Mental Models 7(112), 7-14.

Oliva J.M., Aragón, M.M. (2009) Contribución del aprendizaje con analogías al pensamiento modelizador de los alumnos en ciencias. Enseñanza de las Ciencias 27(2), 195-208.

Parra R.A. (2012) Yogur en la salud humana. Revista Lasallista de Investigación 9(2), 162-177.

Prins G.T. (2010) Teaching and Learning of Modelling in Chemistry Education. Authentic Practices as Contexts for Learning. Leersum, The Netherlands: FSC.

Prins G.T., Bulte A.M.., Van Driel J.H, Pilot A. (2008) Selection of authentic modeling practices as contexts for chemistry education. International Journal of Science Education 30(14), 1867-1890.

Sánchez L. (2005) Reestructuración de los modelos explicativos con respecto al concepto de microorganismos asociados a enfermedad, que conlleve a su aplicación en la industria, mediante el aprendizaje significativo con estudiantes de $8^{a}$ grado en la institución normal de envigado. Medellín (Colombia): Universidad de Antioquia.

Schneider R., Fernández F.J., Aguilar M.B., Guerrero I., Alpuche A., Ponce E. (2006) Partial characterization of a class lla pediocin produced by Pediococcus parvulus 133 strain isolated from mea (Mexican "chorizo"). Food Control 17, 909-915.

Simonneaux L. (2000) A study of pupils' conceptions and reasoning in connection with 'microbes', as a contribution to research in biotechnology education. International Journal of Science Education 22(6), 619-644.

Vosniadou S. (1994) Capturing and modeling the process of conceptual change. Learning and Instruction 4(1), 45-69. 